\title{
ВMJ Global Health Healthcare malpractice and continuing HIV outbreaks in Pakistan
}

\author{
Salima Davlidova, ${ }^{1}$ Syed Hani Abidi, ${ }^{2}$ Syed Ali (iD ${ }^{3}$
}

\begin{abstract}
To cite: Davlidova S, Abidi SH, Ali S. Healthcare malpractice and continuing HIV outbreaks in Pakistan. BMJ Global Health 2019;4:e001920. doi:10.1136/ bmjgh-2019-001920
\end{abstract}

Handling editor Seye Abimbola

SHA and SA contributed equally.

Received 15 August 2019 Revised 19 September 2019 Accepted 21 September 2019

Check for updates

(c) Author(s) (or their employer(s)) 2019. Re-use permitted under CC BY-NC. No commercial re-use. See rights and permissions. Published by BMJ.

${ }^{1}$ Biomedical Sciences, Nazarbayev University School of Medicine, Nur-Sultan, Kazakhstan

${ }^{2}$ Aga Khan University, Karachi, Pakistan

${ }^{3}$ Biomedical Sciences, Nazarbayev University School of Medicine, Astana, Kazakhstan

Correspondence to

Dr Syed Ali; syed.ali@nu.edu.kz
The number of adults and children living with HIV in Pakistan, 150000 in 2017, is anticipated to double by the year $2020 .{ }^{1}$ While the major high-risk groups include transgenders, injection drug users and men who have sex with men, ${ }^{1}$ outbreaks as a result of healthcare malpractice appear to be unusually frequent. In recent years, three such largescale outbreaks were reported in the cities of Gujrat, ${ }^{2}$ Sargodha ${ }^{3}$ and Larkana ${ }^{45}$ (figure 1). Published reports on these outbreaks are sketchy about the origins and routes of transmission, mainly because accurate evidencebased information is missing.

In Gujrat district, the infection, initially discovered when 88 out of $246(36 \%)$ individuals tested positive in an HIV screening camp, is believed to have been endemic for over a decade, silently transmitting among the residents of the Jalalpur Jattan village. Of the individuals interviewed from this village, only $36 \%$ and $34 \%$ were aware that HIV transmission could occur by, respectively, sexual contact and blood transfusion. Such lack of awareness most likely led to the recently reported increase in HIV prevalence in the same village- 750 positive cases in $2018 .^{6}$ Despite efforts made to identify the causes of transmission through contact tracing, only indirect indications were found for transmission through contaminated needles. ${ }^{2}$ While some evidence of sexual transmission was there, an overwhelming number of the study participants reported use of injectable medicine for treatment of illness $(96 \%)$ and invasive surgical $(26 \%) /$ dental $(40 \%)$ procedures. Use of unsafe injection practice is speculated to be a major cause of this endemic. ${ }^{2}$ Epidemic in the village of Kot Imrana, Sargodha, is relatively new. First reported in 2018 with a prevalence rate of $1.3 \%$, the epidemic grew rapidly, reaching $13 \%$ in 2019. ${ }^{3}$ Although some evidence of sexual transmission was found, interviews from patients implicated the origin of transmission to be reuse of contaminated needles by a

\section{Summary box}

In April this year, a large-scale HIV outbreak was reported in Larkana, Pakistan, where to date almost 600 children and 100 adults have been found infected.

- Past such outbreaks, in Gujrat and Sargodha, as a result of uncontrolled transmission, have rapidly expanded into full-blown concentrated epidemics.

- In this article we discuss how a multidisciplinary approach, involving public health and molecular epidemiology experts, needs to be employed to characterise high-risk practices and populations, including the youth, where the infection is currently emerging.

- Harm reduction efforts will then need to be refined and focused on raising awareness and providing vigilant healthcare to those vulnerable populations.

quack who died from AIDS in 2018. As many as 5000 quacks are reported to be practising in the district of Sargodha. The epidemic is clearly growing at an alarming rate; 50 other villages in the vicinity of Sargodha are speculated to be hot spots of HIV infection, with malpractice by quacks being a major threat. ${ }^{3}$

The most recent HIV outbreak was discovered in the city of Larkana, in April 2019. Unfortunately, the infected individuals included 604 children and 135 adults. ${ }^{5}$ Most of the HIV-positive children had HIVnegative parents, indicating that the infection was acquired through horizontal transmission, most probably through contaminated needles used at the private healthcare facilities. ${ }^{7}$ Pursuing that line of enquiry, on May 29, Larkana police registered cases of medical negligence against 24 privately practising doctors. ${ }^{8}$ In addition to malpractice by quacks, other modes of transmission in this outbreak are speculated to be use of contaminated razor blades ${ }^{9}$ and unsafe circumcisions at barber shops. ${ }^{3}$

While healthcare malpractice appears to be the leading cause for the initiation of the above-described outbreaks, lack of awareness about HIV transmission has played the biggest role in facilitating these epidemics and will 


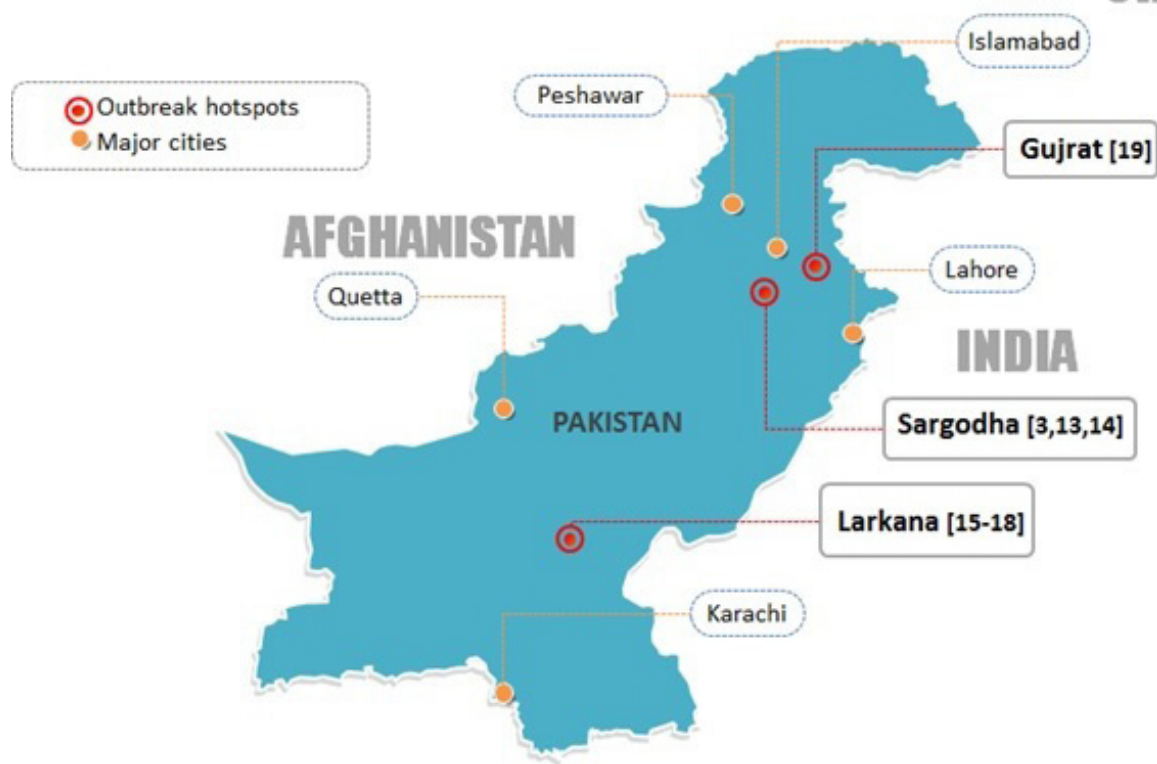

Figure 1 Map of Pakistan showing hot spots of reported HIV outbreaks.

continue to be a major hurdle in any future efforts for harm reduction. According to a United Nations Programme on HIV/AIDS 2017 survey, condom usage was low among major high-risk groups, such as transgenders $(24 \%)$, injection drug users $(15 \%)$ and men who have sex with men (22\%). Knowledge about HIV prevention among young men and women (aged 15-24) was, respectively, $5.2 \%$ and $4.2 \% .^{10}$ The rate at which the epidemic is currently growing in the rural areas alludes to serious gaps in the harm reduction efforts. It is imperative to educate vulnerable masses in the rural areas about treatment and further prevention of transmission. Considering that a major part of the infected population is younger individuals, it is important to target harm reduction efforts to that particular group. In the face of prevailing unawareness, not only the epidemic will continue to spread but will likely give rise to HIV variants that may be hard to treat.

Implications of malpractice in the initiation and lack of awareness in further transmission appear to be the common threads that run through the above-described three stories. However, aside from the interviews from the infected patients, there is no clear-cut evidence, generated through scientifically rigorous analyses, as to the origin and mode of transmission of this infection. In this day and age, molecular analysis of viral sequences is being widely used to study origins and routes of transmission, among other things. Classical cases exist where phylogenetic analyses were successfully used as evidence in courts of law. ${ }^{11}$ In Pakistan as well, phylodynamics has been previously employed to trace origins ${ }^{12}$ and transmission routes of HIV infection. Phylodynamic analysis of HIV gene sequences can reveal information of public health relevance, including origin and hot spots of emerging infections, transmission bridging across demographics and behavioural subgroups, and high-risk groups/practices responsible for the outbreaks/transmission.

The government of Pakistan will have to make a concerted effort in putting together a multidisciplinary approach, bringing together experts of public health, molecular epidemiology and bioinformatics. To generate corroborating evidence of origin and further transmission of these frequent outbreaks, a systematic analysis needs to be conducted that combines data gleaned from patients' interviews and demographic profiling with those generated using phylogenetic analysis of HIV sequences obtained from their blood samples. Implementation of health regulations to control malpractice will prevent future outbreaks, whereas raising awareness among the already infected population will control further transmission and emergence of drug resistance. But before the harm reduction strategies are designed and implemented, it is imperative to characterise the high-risk populations/practices involved in starting and spreading the outbreak. Vulnerable populations thus identified should then be the focus of raising HIV awareness and providing vigilant healthcare and treatment.

Contributors SD: writing of manuscript, analysis of data. SA: writing of the manuscript. SHA: review of the manuscript.

Funding Funding for this study was partially provided by Nazarbayev University (grant: SOM2019002).

Competing interests None declared.

Patient consent for publication Not required.

Provenance and peer review Not commissioned; externally peer reviewed.

Data availability statement № data are available.

Open access This is an open access article distributed in accordance with the Creative Commons Attribution Non Commercial (CC BY-NC 4.0) license, which permits others to distribute, remix, adapt, build upon this work non-commercially, and license their derivative works on different terms, provided the original work is 
properly cited, appropriate credit is given, any changes made indicated, and the use is non-commercial. See: http://creativecommons.org/licenses/by-nc/4.0/.

\section{ORCID iD}

Syed Ali http://orcid.org/0000-0002-9821-1513

\section{REFERENCES}

1. Pakistan Global AIDS Response Progress Report (GARPR). 2015 country progress report Pakistan. National AIDS control program, 2015. Available: https://www.unaids.org/sites/default/files/country/ documents/PAK_narrative_report_2015.pdf

2. Ansari JA, Salman M, Safdar RM, et al. HIV/AIDS outbreak investigation in Jalalpur Jattan (JPJ), Gujrat, Pakistan. J Epidemiol Glob Health 2013;3:261-8.

3. Wahid B. An update on the severe outbreak of HIV in Kot Imrana, Pakistan. Lancet Infect Dis 2019;19:241.
4. http://time.com/5594524/larkana-pakistan-hiv-outbreak/

5. https://www.thenews.com.pk/latest/481688-who-declares-hivoutbreak-in-larkana-as-grade-2-emergency

6. https://www.thenews.com.pk/print/401146-750-hiv-positive-casesin-jalalpur-jattan

7. Altaf A, lqbal S, Shah SA. A third major human immunodeficiency viruses (HIV) outbreak in Larkana, Pakistan: caused by unsafe injection practices. J Pak Med Assoc 2019;69:1068-9.

8. https://www.samaa.tv/news/2019/05/larkana-hiv-crisis-will-mychild-make-it/

9. Zaid M, Ali M, Afzal MS. HIV outbreaks in Pakistan. Lancet HIV 2019;6:e418-9.

10. https://www.unaids.org/en/regionscountries/countries/pakistan

11. de Oliveira T, Pybus OG, Rambaut A, et al. HIV-1 and HCV sequences from Libyan outbreak. Nature 2006;444:836-7.

12. Khan S, Rai MA, Khanani MR, et al. HIV-1 subtype A infection in a community of intravenous drug users in Pakistan. BMC Infect Dis 2006;6:164. 